\title{
Nodal Donovanosis as the Sentinel Clue to Acquired Immunodeficiency Syndrome
}

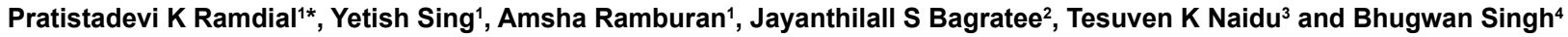

${ }^{1}$ Departments of Anatomical Pathology, National Health Laboratory Service \& University of KwaZulu-Natal, South Africa

${ }^{2}$ Obstetrics and Gynaecology, University of KwaZulu-Natal, Durban, KwaZulu-Natal, South Africa

${ }^{3}$ Otorhinolaryngology, University of KwaZulu-Natal, Durban, KwaZulu-Natal, South Africa

${ }^{4}$ General Surgery, University of KwaZulu-Natal, Durban, KwaZulu-Natal, South Africa

\begin{abstract}
Objective: Donovanosis, caused by Calymmatobacterium granulomatis, is a recognized cause of genital ulcer disease. Extragenital donovanosis in acquired immunodeficiency syndrome (AIDS) and lymph nodes is documented rarely. The aim of this report is to highlight implications of lymph node involvement as the initial manifestation of donovanosis, especially in AIDS.
\end{abstract}

Materials and methods: This is a retrospective clinicopathological 6 year study that reviewed the features of lymph node biopsies and patients presenting with nodal donovanosis.

Results: Of a total of 198 patients with donovanosis, 4 patients with nodal disease were identified. Patient 1 , on anti-tuberculous therapy for pulmonary tuberculosis for 2 weeks, developed subcutaneous nodules on her legs and left-sided inguinal lymphadenopathy. Biopsies confirmed erythema induratum and nodal donovanosis in the former and latter sites, respectively. Patients 2 and 3 presented with right-sided inguinal lymphadenopathy that simulated lymphoma. Lymph node biopsy confirmed donovanosis. Further examination on follow-up, confirmed ulcers on the cervix and penis, in patients 2 and 3, respectively. Biopsies of these genital ulcers demonstrated donovanosis in both patients. Patient 4 presented with a left-sided neck mass, biopsy of which confirmed nodal donovanosis. Subsequent biopsy of a pre-auricular ulcer and of the cervix confirmed donovanosis. HIV seropositivity and AIDS were confirmed in all patients. Patient 1 died of pulmonary tuberculosis while disease resolution was achieved in the others following 4-6 weeks of trimethoprim-sulfamethoxazole treatment.

Conclusion: Heightened clinicopathological recognition of nodal donovanosis, lymph node biopsy and careful histomorphological assessment thereof are pivotal, not only for diagnostic confirmation of nodal donovanosis and its distinction from other common nodal infections, especially in the AIDS context, but also as a sentinel clue to genital donovanosis, HIV infection and AIDS.

Keywords: Lymph node; Nodal; Donovanosis; Granuloma inguinale; AIDS

\section{Introduction}

Donovanosis [granuloma inguinale] is caused by Calymmatobacterium granulomatis, a Gram-negative, facultative, obligate, intracellular, pleomorphic bacterium that is phylogenetically most closely related to and placed within the Klebsiella genus [1-3]. Categorized as a cause of genital ulcer disease, it typically forms painless, beefy red genital ulcers with raised margins and a friable clean base $[3,4]$. Auto-inoculation, hematogenous spread and oral sex have been implicated in the pathogenesis of extragenital donovanosis that occurs in $3-6 \%$ of patients [5], mainly in the lip, gums, cheek, palate, pharynx, neck, nose, larynx, chest, bone and liver [1,6]. Lymph node involvement by C. granulomatosis is documented rarely in the literature, mainly as case reports in the pre-acquired immunodeficiency syndrome (AIDS) era [6-16]. Notwithstanding these contributions to the global literature, to date, extragenital donovanosis in human immunodeficiency virus (HIV)-infected patients is documented very rarely [5,11]. Only one HIV-positive child with cervical nodal donovanosis is reported in the literature up to now [11].

In reporting nodal donovanosis in 4 patients, we highlight donovanosis as a rarely documented cause of lymphadenopathy in general, and in the context of AIDS, in particular. In so doing, we detail the histopathological features and highlight the importance of lymph node biopsy in the distinction of donovanosis from a range of disseminated infective processes, the majority AIDS-defining.

\section{Methods}

All biopsies reported as "donovanosis" or "granuloma inguinale" from 1 January 2008 to 31 December 2013 were retrieved from the departmental archive using the SNOMED word and code search engines. The results of this search were analysed to identify cases with lymph node involvement. Electronic and manual links to multiple biopsies allowed review of biopsies from multiple locations in the same patient. Only those cases in which adequate clinical information (age/ sex, presenting problem, distribution of disease, HIV status, other comorbid diseases) was available were included in the study. All biopsies had been preserved in formalin and subjected to routine processing and embedding in paraffin wax. Stored slides or sections that were re-cut and stained at $3 \mu \mathrm{m}$ (hematoxylin and eosin, Giemsa and Warthin Starry silver, Fontana Masson silver, methenamine silver, Fite-Faraco, Ziehl

*Corresponding author: PK Ramdial, Department of Anatomical Pathology, Leve 3, Laboratory Building, Inkosi Albert Luthuli Central Hospital, 800 Bellair Road, Mayville, 4058, KwaZulu-Natal, South Africa, Tel: +27 (0)31 2402693; E-mail: ramdial@ukzn.ac.za

Received July 25, 2016; Accepted August 19, 2016; Published August 26, 2016

Citation: Ramdial PK, Sing Y, Ramburan A, Bagratee JS, Naidu TK, et al. (2016) Nodal Donovanosis as the Sentinel Clue to Acquired Immunodeficiency Syndrome. J AIDS Clin Res 7: 614. doi: 10.4172/2155-6113.1000614

Copyright: (c) 2016 Ramdial PK, et al. This is an open-access article distributed under the terms of the Creative Commons Attribution License, which permits unrestricted use, distribution, and reproduction in any medium, provided the original author and source are credited. 
Neelsen, Southgate mucicarmine and periodic acid Schiff stains) were re-appraised. Immunohistochemistry, undertaken manually on sections cut at $2 \mu \mathrm{m}$ thickness, employed heat-assisted microwave antigen retrieval and the Novolink polymer detection system [Vision Biosystems (Europe) Ltd, Newcastle-upon-Tyne, UK] with diaminobenzidine chromogen for antibody visualization. The immunohistochemical stains that were appraised to confirm nodal germinal centres included CD35 (Ber-MAC-DRC), CD21 (1F8) and D2-40 (D2-40) from Dakopatts, Carpinteria, Denmark. Appropriate positive and negative controls were used. To determine the identity of the organisms observed polymerase chain reaction (PCR) and nucleotide sequencing were undertaken. Briefly, DNA was extracted from formalin-fixed paraffinwax embedded tissue using the QIAamp FFPE DNA extraction kit (Qiagen, Valencia, CA, USA) according to manufacturer's instruction. To assess the integrity of the extracted DNA, PCR for a 309-base pair segment of the beta actin gene [17] was performed followed by PCR for the Acetolactate synthase (iluK) gene (accession number: AF009239) [18] using primers F-5 '-AACCCGATCTTCCTGCTC-3' and R-5'CCACATCGCCTGTTCGTATTC- $3^{\prime}$ and the FastStart Taq DNA polymerase PCR kit (Roche Bioscience, Palo Alto, CA, USA) according to the manufacturer's instruction. In silico validation of these primers showed specificity for the Klebsiella genus. Fifteen nanograms of genomic DNA were used in each $25 \mu$ reaction. Nucleotide sequencing of this product using the $i l u K$ forward primer was performed by Inqaba Biotechnical Industries (Inqaba Biotechnical Industries, Pretoria, South Africa) to confirm C. granulomatis.

\section{Results}

Of 198 patients that were diagnosed as donovanosis/granuloma inguinale in the study period, $4(2.02 \%)$ biopsies from 4 HIVseropositive patients with AIDS and adequate clinical information (Table 1) involved lymph nodes and form the study cohort.

\section{Clinical details}

The average patient age was 31 (range $=21-43$ ) years. Donovanosis was not a clinical consideration for the genital and extragenital infection of any patient, but a malignancy and tuberculosis were considered in 3 patients (Table 1).

After 2 weeks of anti-tuberculous therapy for pulmonary tuberculosis, patient 1 developed disseminated cutaneous, variably ulceronecrotic papular and subcutaneous nodular lesions on her legs that were clinically compatible with erythema induratum, a hypersensitivity manifestation of cutaneous tuberculosis. A small, non-tender, left-sided inguinal lymph node was identified. Biopsy of the leg nodule confirmed erythema induratum and biopsy of the inguinal lymph node demonstrated donovanosis. Subsequent followup and genital examination demonstrated cervical ulceration; biopsy of this confirmed donovanosis. Extrapulmonary tuberculosis was not confirmed.

Patients 2 and 3 presented with right-sided, palpable, non-tender inguinal lymphadenopathy, approximately $2 \mathrm{~cm}$ in diameter. The clinical impression was that of lymphoma or tuberculosis. Lymph node biopsies from both patients demonstrated donovanosis. Further examination of patients 2 and 3 at 6 and 8 week follow-up respectively, revealed a vaginal discharge and ulceration of the cervix in patient 2 and a non-tender, ulceronecrotic penile lesion, $12 \times 12 \mathrm{~mm}$ in greater dimensions in patient 3 . Biopsies of the genital lesions confirmed donovanosis in both patients.

Patient 4 sought medical attention for an enlarging, left-sided neck mass of 6 months duration. On examination a left-sided neck mass, approximately $4 \mathrm{~cm}$ in largest diameter, assumed to be matted lymph nodes, was palpated. In addition, an acneiform facial eruption with papular, papulopustular and pigmented scarring lesions was identified. A pre-auricular, $8 \times 5 \mathrm{~mm}$ ulceronodular lesion, was present that was assumed to be part of the acneiform eruption. The clinical impression was that of lymphoma and acne. Biopsy of the matted neck lymph nodes revealed donovanosis. Subsequent examination of the female genital tract confirmed a firm nodular lesion on the posterior lip of the cervix. The cervical lesion and pre-auricular facial ulcer, that had increased to $20 \times 12 \mathrm{~mm}$ in larger dimensions, were biopsied. Both biopsies demonstrated donovanosis. Outcome: HIV seropositivity and AIDS was subsequently confirmed in all patients. None had additional AIDS-associated co-morbid disease. Patient 1 succumbed to pulmonary tuberculosis. The other patients were treated with trimethoprimsulfamethoxazole and a cutaneous response to therapy was confirmed after 4-6 weeks of therapy. The acne in patient 4 was also treated with topical antibiotics.

All patients were referred to local anti-retroviral clinics for further management. They did not return to the referral hospitals for additional follow-up.

\section{Spectrum of nodal histopathological findings}

The lymph node biopsies from patients 1, 2 and 3 demonstrated smooth contours and variable effacement by granulation tissue containing a dense inflammatory infiltrate composed of plasma cells, aggregates of neutrophils and histiocytes with intracytoplasmic Donovan bodies (Figure 1). Residual nodal tissue and capsular extension of the inflammatory process were noted (Figure 2). The former was identified by nodal subcapsular sinus patency (Figures $2 \mathrm{a}$ and $2 \mathrm{~b}$ ) and scattered, compressed, atrophic and reactive cortical germinal centers that were highlighted by CD21 (Figure 2c), CD35

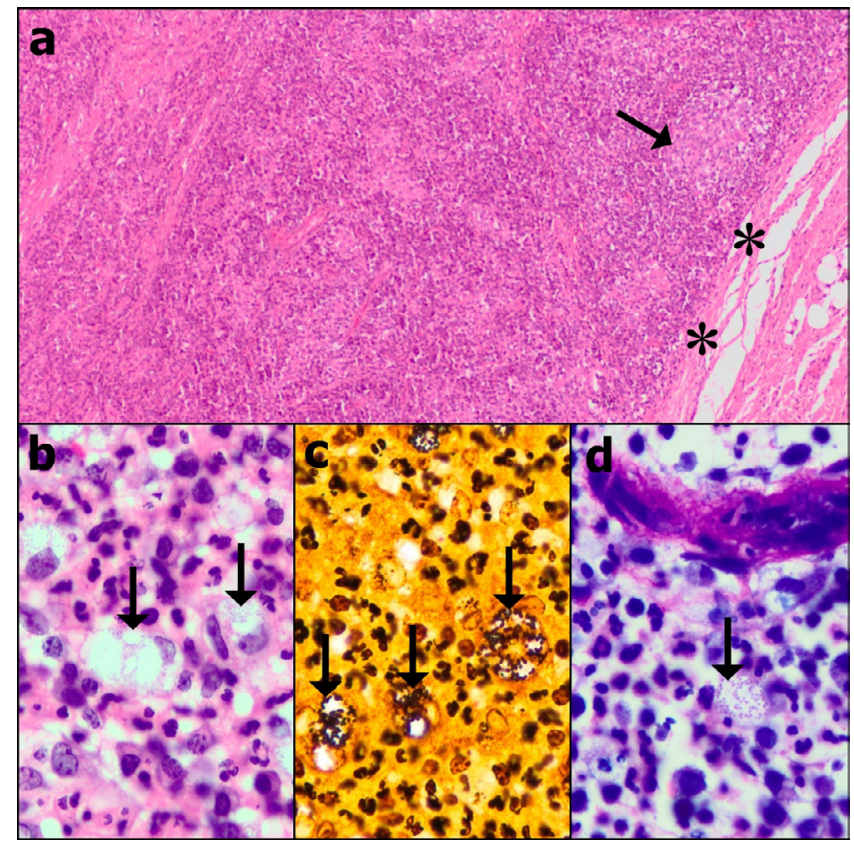

Figure 1: Lymph node effaced by donovanosis (a) but intact capsule (asterisks) and focal reactive germinal centers (arrow) are noted [Hematoxylin \& eosin] High power demonstration of plasma cells, neutrophils and Donovan bodies (arrow) (b) [Hematoxylin \& eosin]. Donovan bodies highlighted on Warthin Starry silver (arrows) (c) and Giemsa (arrow) (d) stained sections. 
Citation: Ramdial PK, Sing Y, Ramburan A, Bagratee JS, Naidu TK, et al. (2016) Nodal Donovanosis as the Sentinel Clue to Acquired Immunodeficiency Syndrome. J AIDS Clin Res 7: 614. doi: 10.4172/2155-6113.1000614

(Figure 2d) and D2-40 immunohistochemical stains. In addition, in 2 of the 4 matted lymph nodes from patient 4 , the smooth contour was maintained but extracapsular fibrosis was evident (Figure 3a). In the remaining 2 matted lymph nodes, effacement by donovanosis and foci of irregular extracapsular extension into the surrounding fatty tissue (Figure $3 b$ ) were present. Granulomas or necrosis were not evident.

PCR amplification of the 255-base pair Acetolactate synthase gene segment confirmed the presence of a Klebsiella genus organism in 3 lymph nodes, from patients 1, 2 and 4 that had adequate material for molecular investigation. Subsequent nucleotide sequencing and Basic Local Alignment Search Tool (BLAST) investigation showed that this sequence shared $100 \%$ identity to the iluK gene of Calymmatobacterium granulomatis (Figure 4) in all 3 biopsies.

\section{Discussion}

The natural history, treatment, disease classification and nomenclature of donovanosis remain controversial [1]. Although McLeod originally labeled the disease as "serpiginous ulcer" in 1882, the rubric "granuloma inguinale" was subsequently introduced to depict the presence of granulation tissue and the common localization of the disease to the inguinal area. "Donovanosis" was coined in 1950 in honor of Donovan, who had pioneered the discovery of the causative infective agent in 1905 [19]. Donovan named the organism Calymmatobacterium granulomatis ("kalymma": Greek for "hood or veil") to mirror its pseudo-encapsulated appearance in tissue sections [20]. A major cause of genital ulcers in tropical and subtropical regions of the world, donovanosis is endemic in southeast India, Brazil, the Caribbean, Papua New Guinea, northern Australia and Africa, including regions of South Africa [21,22]. It is generally regarded as a sexually transmitted infection with an incubation period of 2 weeks to 6 months $[1,21,22]$. Cutaneous and subcutaneous papules and nodules ulcerate to form hypertrophic, verrucous or foul-smelling destructive, deep ulcers and deformative, fibrosing, cicatrizing lesions $[1,21]$. Untreated, donovanosis is a persistent and progressive, mutilating disease that may evolve into abscesses and fistulae [19].

While donovanosis usually affects the dermis and subcutaneous tissue of the genital area, contiguous spread to the perianal and inguinal regions is well-recognized [23]. Hematogenous spread to distant organs, inclusive of bone, joints, lung, liver and spleen has been documented, especially at autopsy $[5,6,20,22,23]$. Auto-inoculation of genito-inguinal disease to head and neck structures, including the scalp, orbit, lips and oral cavity is also reported rarely $[23,24]$. The presence of inguinal swellings, referred to as "pseudobuboes", is attributed to the tumor-like masses formed by the florid growth of subcutaneous granulation tissue [21]. Lymphadenopathy caused by donovanosis is a rarely reported phenomenon [6-13]. It has been suggested that the presence of subcutaneous nodules may be mistaken for extragenital nodal disease. Some workers believe that, even in the presence of extensive disease, regional lymph nodes are not enlarged, painful or

\begin{tabular}{|c|c|c|c|c|c|c|}
\hline P/No. & Age/Sex & LN site & Ulcer sites & Extranodal biopsies & CD4 \\
\hline 1 & $23 / F$ & L inguinal & Cervix & Cervix, skin & PTB, skin TB (EI) \\
\hline 2 & $21 / F$ & R inguinal & Cervix & Cervix & Lymphoma or TB \\
\hline 3 & $37 / M$ & R inguinal & Penis & Penis & Lymphoma orTB \\
\hline 4 & $43 / F$ & L neck & Pre-auricular & Cervix, skin & 91 \\
\hline
\end{tabular}

CD4: CD4 cell count in cells/mm³; El: Erythema Induratum; F: Female; L: Left; LN: Lymph Node; LN site: Lymph Node Biopsy Site; M: Male; P/No.: Number; PTB: Pulmonary Tuberculosis; PV: Per Vaginal; R: Right; TB: Tuberculosis

Table 1: Summary of clinical findings

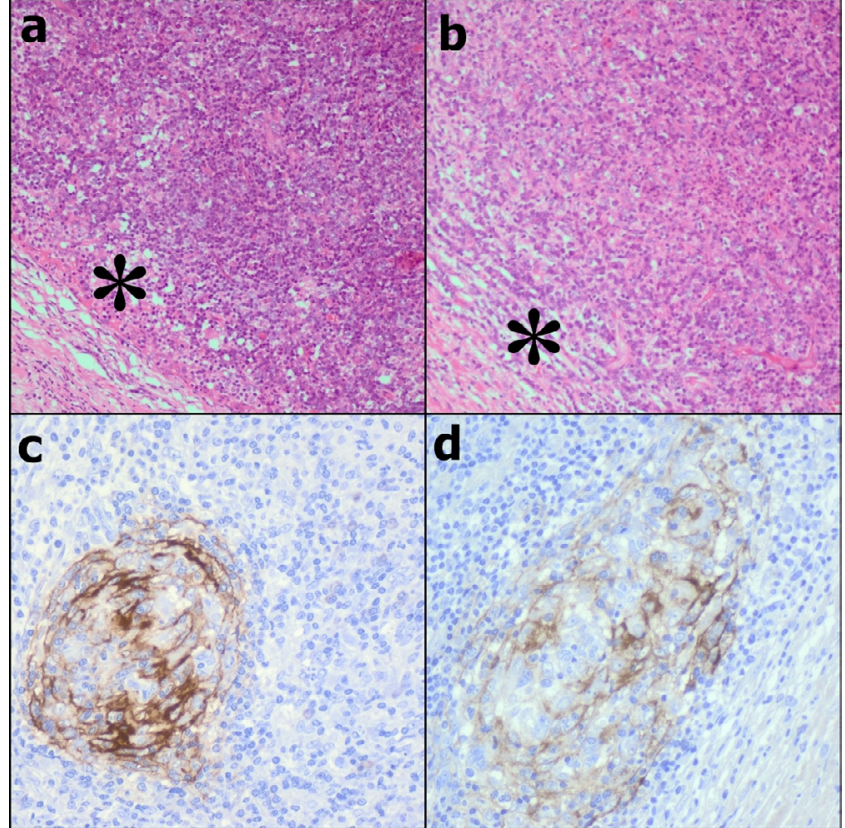

Figure 2: Identifiable patent subcapsular sinus (asterisk) (a) and capsular involvement by donovanosis (asterisk) (b) [Hematoxylin \& eosin]. Germinal centers highlighted by CD21(c) and CD35 (d) immunostains.

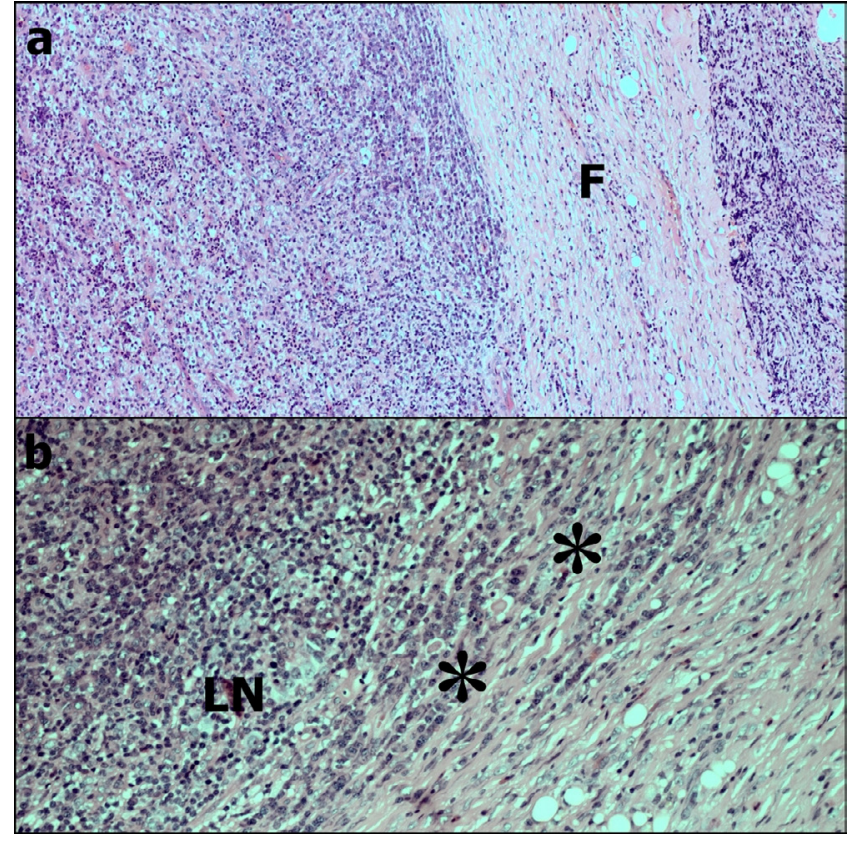

Figure 3: Patient 4: Internodal fibrosis $(F)$ between 2 effaced lymph nodes with smooth contours (a) [Hematoxylin \& eosin]. Nodal donovanosis (LN) (b) and extranodal extension of the disease (asterisks). 


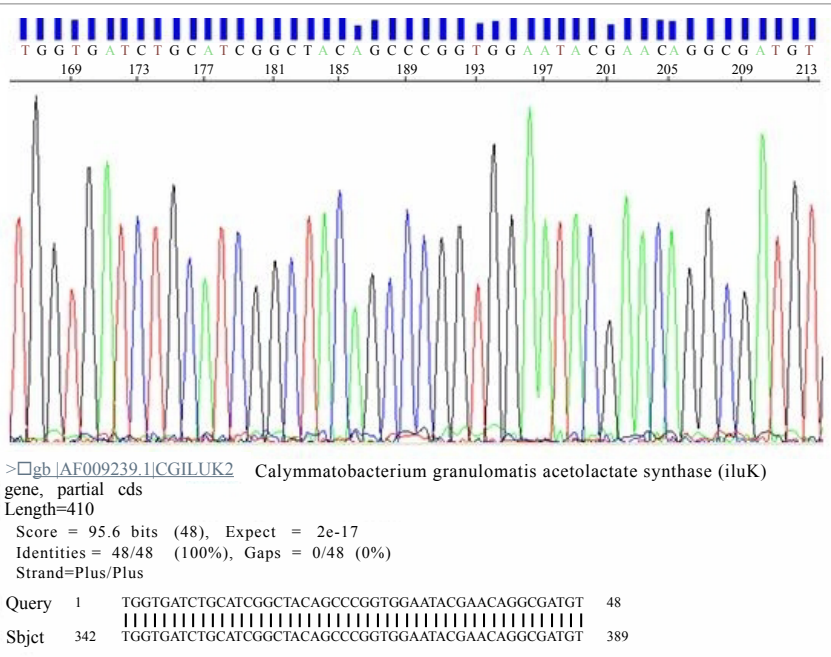

Figure 4: An electropherogram generated by an Applied Biosystems 3500XL genetic analyzer demonstrating the sequence of Calymmatobacterium granulomatis acetolactate synthase (iluK) gene, congruent with the diagnosis of donovanosis.

tender $[21,25]$. While the lymphatics in the genito-inguinal area may be widely dilated and associated with cicatrization and genital swelling [26], dye injection studies have confirmed that they are not obstructed [21]. In the presence of extensive tissue destruction and inflammation, secondary lymphadenopathy on the basis of superimposed infection is hypothesized [14]. In contrast, other writers have argued that lymphatic and nodal spread of donovanosis is a distinct clinicopathological characteristic of the disease [6-13].

In the present study, nodal donovanosis was identified in diverse anatomical locations during the clinical assessment of patients for potential malignancy or tuberculosis. These lymph nodes were palpable, of variable size, non-tender and matted or discrete. Genital or extragenital ulceronodular lesions were evident, but there was no mutilating disease, oedema or fistulae. Microscopically, the lymph nodes demonstrated diverse features. Some were partially effaced by donovanosis. In these nodes the presence of patent subcapsular sinuses and atrophic or reactive germinal centres confirmed residual nodal morphology indicating that they represented intranodal and not subcutaneous nodules of donovanosis. Other lymph nodes demonstrated total effacement by donovanosis and capsular and extracapsular extension of the disease. Biopsy of the lymph nodes underpinned confirmation of nodal donovanosis. Patients 2, 3 and 4 had presented for medical attention of inguinal and cervical masses and had ignored the vaginal discharge and cutaneous ulcerative lesions. Although speculative, it may be that lymphadenopathy in patients presenting with mucocutaneous disease symptoms is overlooked and that nodal donovanosis maybe an under-recognized phenomenon. The underpinning causes of nodal involvement in donovanosis remain unclear.

Extragenital, including nodal, donovanosis may be viewed as a consequence of the co-morbidity associated with advanced AIDS, especially as all the patients in the present study had low CD4 lymphocyte counts. While sexually transmitted diseases, including donovanosis, are associated with the heightened spread of HIV infection, in a study on pregnant women with donovanosis, neither the clinical appearance nor outcome was altered by HIV infection [1,27]. In contrast, Jemkhedkar et al. [28] reported that the ulcer size and clinical presentations of donovanosis between HIV-seropositive and seronegative patients were not statistically different, but the ulcers were associated with greater tissue destruction and longer healing times. Hence, while it is tempting to speculate AIDS-associated immunocompromize as a cause for nodal spread, studies encompassing larger numbers of lymph node biopsies are necessary to confirm such an association.

A range of infective diseases may mimic nodal donovanosis in inguinal and extra-inguinal locations. Acute lymphadenitis with an abscessing morphology, characterized by variable suppuration and granulation tissue with a macrophagic phagocytic response may mimic the presence of histiocytes containing Donovan bodies. Histomorphological suspicion and careful appraisal of the morphology of the histiocytic contents, including oil immersion appraisal, are critical to the recognition of Donovan bodies and subsequent conduction of diagnostic, special stains. Whilst typical mycobacterial responses of $M$. tuberculosis and mycobacteria other than tuberculosis are granulomatous in nature, in immunocompromised individuals and in the earliest stage of the disease, neutrophils predominate [29]. In these setting, special stains for mycobacteria reveal myriad acid fast bacilli. Rhinoscleroma, caused by $K$. rhinoscleromatis, contains Mikulicz cells that are parasitized by organisms that mimic Donovan bodies [10]. However, the background differs from that of donovanosis because it is typified by an infiltrate of Russell body-rich plasma cells and lymphocytes; neutrophil micro-abscesses are not a feature. In doubtful cases, PCR testing and nucleotide sequencing investigations will differentiate between $K$. rhinoscleromatis and C. granulomatis. While fungal (histoplasmosis, cryptococcosis, pneumocystosis) [30] and protozoal (toxoplasmosis, leishmaniasis) [31] infections are characterized by the presence of micro-organisms within the expanded cytoplasm of histiocytes, these diseases often demonstrate a granulomatous response, the histiocytes may have a foamy appearance, and, the organisms are generally larger and have a round to oval rather than elongated bacillary shape.

\section{Conclusion}

Extragenital disease is an uncommon manifestation of donovanosis. Heightened awareness of its occurrence and histomorphological features are pivotal to accurate diagnosis. In addition, increased recognition of donovanosis as a cause of lymphadenopathy, a common clinical finding in patients with HIV infection and AIDS, is necessary not only for optimal clinicopathological investigation, diagnosis and patient management, but also as a sentinel of HIV infection and AIDS. In this study, lymph node biopsy not only confirmed involvement by donovanosis, but also facilitated the distinction of nodal donovanosis from other more common nodal infections, especially in the context of AIDS, and from subcutaneous nodules of donovanosis that may masquerade as enlarged lymph nodes clinically. While the underpinning causes of nodal involvement in donovanosis remain unclear, the occurrence in patients with AIDS in the present study, urges speculation that AIDS-associated immunocompromize is the cause of nodal spread. Prospective studies encompassing careful appraisal of all patients with donovanosis for lymphadenopathy, and lymph node biopsy for histopathological assessment are suggested to adequately investigate any potential association.

\section{Acknowledgement}

Mrs. M Moodley for manuscript typing and literature retrieval, Mr. D Sookhdeo and Ms. YAS Karrim for laboratory work and data tracing and the National Health Laboratory Service management for support of research initiatives. The study was conducted in accordance with the ethical guidelines of the University of KwaZuluNatal. 
Citation: Ramdial PK, Sing Y, Ramburan A, Bagratee JS, Naidu TK, et al. (2016) Nodal Donovanosis as the Sentinel Clue to Acquired Immunodeficiency Syndrome. J AIDS Clin Res 7: 614. doi: 10.4172/2155-6113.1000614

Page 5 of 5

\section{References}

1. O'Farrell N (2002) Donovanosis. Sex Transm Infect 78: 452-457.

2. Wu JJ, Huang DB, Pang KR, Tyring SK (2004) Selected sexually transmitted diseases and their relationship to HIV. Clin Dermatol 22: 499-508.

3. Carter JS, Bowden FJ, Bastian I, Myers GM, Sriprakash KS, et al. (1999) Phylogenetic evidence for reclassification of Calymmatobacterium granulomatis as Klebsiella granulomatis comb. nov. Int J System Bacteriol 49: 1695-1700.

4. O'Farrell N (1993) Clinico-epidemiological study of donovanosis in Durban, South Africa. Genitourin Med 69: 108-111.

5. Sanders CJ (1998) Extragenital donovanosis in a patient with AIDS. Sex Transm Infect 74: 142-143.

6. Rajam RV, Rangiah PN, Anguli VC (1954) Systemic donovaniasis. Br J Vener Dis 30: $73-80$.

7. Bowden FJ, Bright A, Rode JW, Brewster D (2000) Donovanosis causing cervical lymphadenopathy in a five-month-old boy. Pediatr Infect Dis J 19: 167-169.

8. Brigden M, Guard R (1980) Extragenital granuloma inguinale in North Queensland. Med J Aust 2: 565-567.

9. Jennison DB, Helwig EB, Milstone JH (1947) Granuloma inguinale involving buttock and lymph node; cultivation of the Donovan body in embryonic yolk. Arch Derm Syphilol 55: 342-354.

10. Freinkel AL (1988) Granuloma inguinale of cervical lymph nodes simulating tuberculous lymphadenitis: Two case reports and review of published reports. Genitourin Med 64: 339-343.

11. Govender D, Hadley GP, Donnellan R (1999) Granuloma inguinale (donovanosis) presenting as a neck mass in an infant. Pediatr Surg Int 15 : 129-131.

12. Greenblatt RB, Dienst RB, Pund ER, Torpin R (1939) Experimental and clinical granuloma inguinale. JAMA 113: 1109-1116.

13. Sobel N, Pensky N (1943) Bubonulus in granuloma inguinale. Arch Dermatol Syphilol 48: 494-496.

14. Sehgal VN, Sharma NL, Bhargava NC, Nayar M, Chandra M (1979) Primary extragenital disseminated cutaneous donovanosis. $\mathrm{Br} J$ Dermatol 101: 353-356.

15. Kuberski T (1980) Granuloma inguinale (donovanosis). Sex Transm Dis 7: 29-36.

16. Richens J (1985) Donovanosis--a review. P N G Med J 28: 67-74.
17. Richter E, Schlüter C, Duchrow M, Hahn M, Rüsch-Gerdes S, et al. (1995) An improved method for the species-specific assessment of mycobacteria in routinely formalin-fixed and paraffin-embedded tissues. J Pathol 175: 85-92.

18. http://www.ncbi.nlm.nih.gov/nucleotide/4558382?report=genbank\&log $\$=$ nuclto p\&blast_rank=1\&RID=1XASP25T016

19. Rashid RM, Janjua SA, Khachemoune A (2006) Granuloma inguinale: A case report. Dermatol Online J 12: 14.

20. West W, Fletcher H, Hanchard B, Rattray C, Vaughan K (2005) Bilateral psoas abscess in a case of granuloma inguinale. West Indian Med J 54: 343-345.

21. Majmudar B (1997) Granuloma inguinale (Donovanosis). Pathology of Infectious Diseases. Appleton \& Lange, Stamford, Connecticut: 565-570.

22. Paterson DL (1998) Disseminated donovanosis (granuloma inguinale) causing spinal cord compression: Case report and review of donovanosis involving bone. Clin Infect Dis 26: 379-383.

23. Spagnolo DV, Coburn PR, Cream JJ, Azadian BS (1984) Extragenital granuloma inguinale (Donovanosis) diagnosed in the United Kingdom: A clinical, histological, and electron microscopical study. J Clin Pathol 37: 945-949.

24. Coovadia YM, Steinberg JL, Kharsany A (1985) Granuloma inguinale (donovanosis) of the oral cavity. A case report. S Afr Med J 68: 815-817.

25. Richens J (1994) Sexually transmitted diseases in children in developing countries. Genitourin Med 70: 278-283.

26. Wistrand $R$, Wegerhoff $F$ (1985) Granuloma inguinale in the eastern Transvaal. S Afr Med J 67: 13-15.

27. Hoosen AA, Mphatsoe M, Kharsany AB, Moodley J, Bassa A, et al. (1996) Granuloma inguinale in association with pregnancy and HIV infection. Int $J$ Gynaecol Obstet 53: 133-138.

28. Jamkhedkar PP, Hira SK, Shroff HJ, Lanjewar DN (1998) Clinico-epidemiological features of granuloma inguinale in the era of acquired immune deficiency syndrome. Sex Transm Dis 25: 196-200.

29. Ramdial PK (2010) Dermatopathological challenges in the human immunodeficiency virus and acquired immunodeficiency syndrome era. Histopathology 56: 39-56.

30. David EE (2009) Fungal diseases. Lever's Histopathology of the skin 591-620

31. Sellheyer K, Heneke E (2009) Protozoan diseases and parasitic infestations Lever's Histopathology of the skin. Lippincott Williams \& Wilkins, Philadelphia: $621-36$ 